\title{
Peralihan Rezim Tektonik: Implikasinya pada Konsentrasi Torium di Mamasa dan Tana Toraja, Sulawesi-Indonesia
}

\section{Tectonic Regime Transition: Implications for Thorium Concentrations in Mamasa and Tana Toraja, Sulawesi-Indonesia}

\author{
Sugeng Purwo Saputro ${ }^{1 *}$, Dwi Ratih Purwaningsih ${ }^{2}$, Bambang Priadi $^{3}$ \\ ${ }^{1}$ Pusat Penelitian Geoteknologi (LIPI), Jl. Sangkuriang, Bandung, Indonesia, 40135 \\ ${ }^{2}$ Program Studi Kimia, Fakultas Matematika dan Ilmu Pengetahuan Alam (FMIPA)-ITB, \\ ${ }^{3}$ Program Studi Teknik Geologi, Fakultas Ilmu dan Teknologi Kebumian (FITB)-ITB, \\ Jl. Ganesha No. 10, Bandung, Indonesia, 40132 \\ *E-mail: sugeng.purwo.saputro@lipi.go.id
}

Naskah diterima: 19 Oktober 2020, direvisi: 16 November 2020, disetujui: 24 November 2020

DOI: 10.17146/eksplorium.2020.41.2.6063

\begin{abstract}
ABSTRAK
Mamasa dan Tana Toraja secara geografis merupakan bagian dari lengan barat Pulau Sulawesi. Batuanbatuan mafik di daerah tersebut dan sekitarnya memiliki nilai laju radiasi tinggi dan anomali kandungan torium (Th). Penelitian ini bertujuan untuk mengetahui mekanisme tataan tektonik yang berperan dalam peningkatan konsentrasi Th. Enam sampel batuan dianalisis menggunakan analisis petrografi dan geokimia (AAS, ICP-MS, NA, dan XRF), dilengkapi dengan pentarikhan umur menggunakan metode ${ }^{40} \mathrm{~K}-{ }^{40} \mathrm{Ar}$ pada sampel batuan terpilih. Pengamatan petrografi memperlihatkan kehadiran mineral plagioklas, olivin, piroksen, hornblenda, nefelin, dan alanit pada batuan yang diidentifikasi sebagai nefelin-basanit, basalt, trakhibasalt, dan gabro. Sejumlah tekstur yang tampak pada batuan tersebut mengindikasikan kontaminasi dan perubahan kondisi tektonik. Analisis geokimia menunjukkan bahwa nefelin-basanit, basalt, trakhibasalt, dan gabro (absarokit) terbentuk pada batas kontinental aktif (ACM) yang sedang mengalami transisi dari subduksi aktif (penunjaman ke arah barat) menjadi post-subduksi. Perubahan tataan tektonik membuat magma membeku pada kondisi yang sangat ekstrim. Proses pembekuan magma diinterpretasikan terjadi pada umur sekitar 13,10-11,02 Ma. Mekanisme tersebut berperan penting terhadap terjadinya peningkatan konsentrasi torium di Mamasa dan Tana Toraja.
\end{abstract}

Kata kunci: Torium, Tana Toraja, potasium-argon, alanit, post-subduksi

\begin{abstract}
Mamasa and Tana Toraja geographically are part of the western arm of Sulawesi Island. The mafic rocks in these areas and their surroundings have high radiation dose rate and thorium (Th) anomaly content. This research aim is to determine tectonic setting mechanism which play the important role on the increasing of Th concentration. Six rock samples were analysed using petrography and geochemical analyses (AAS, ICP-MS, NA, and XRF) completed with the ${ }^{40} K-{ }^{40} A r$ dating on selected rock samples. Petrography observations show plagioclase, olivine, pyroxene, hornblende, nepheline, and allanite minerals presence in the rocks which identified as nepheline-basanite, basalt, trachybasalt, and gabbro. Numbers of texture appearances in the rocks indicate contamination and changes on tectonic setting. Geochemistry analysis shows that nepheline-basanite, basalt, trachybasalt, and gabbro (absarokite) were formed at the active continental margin (ACM), which is undergoing active subduction (westward subduction) to post-subduction transition. The changing of tectonic setting made magma solidify in extreme conditions. The magma solidify process is interpreted to occur at the age of 13.10-11.02 Ma. These mechanisms play an important role for the increase of thorium concentration in Mamasa and Tana Toraja.
\end{abstract}

Keywords: Thorium, Tana Toraja, potassium-argon, allanite, post-subduction 


\section{PENDAHULUAN}

Torium (Th) secara umum didefinisikan sebagai unsur refraktori terkondensasi yang berasal dari nebula matahari, dengan temperatur pembentukan $>1.400$ Kelvin $(\mathrm{K})$ [1]. Temperatur yang sangat tinggi tersebut membuat Th di bumi hanya dapat terbentuk pada bagian inti bumi hingga mantel bumi. Konsentrasi yang dihasilkan dari proses pembentukan serta luas sebarannya juga sangat terbatas dan lokal [1].

Torium (Th) secara umum termasuk dalam kelompok unsur radioaktif yang memiliki tingkat radiasi cukup tinggi dan bersifat tidak stabil. Hal tersebut membuat Th banyak dimanfaatkan sebagai bagian dari sistem Pembangkit Listrik Tenaga Nuklir (PLTN). Dalam perkembangannya, PLTN dinilai dapat menghasilkan energi dengan kuantitas yang lebih besar namun tetap ramah lingkungan. Di sisi lain, jika dalam pemanfaatannya dilakukan secara sembarangan atau kehadirannya di alam melebihi batas normal, maka Th dapat menimbulkan bahaya berupa radiasi pada makhluk hidup yang berada di sekitarnya.

Indonesia tercatat memiliki beberapa daerah dengan nilai laju radiasi (radioaktivitas) Th yang tergolong tinggi, salah satunya di daerah sekitar Mamuju [2], [3]. Radioaktivitas tinggi di daerah tersebut tercermin dari banyaknya hasil pelapukan batuan kaya Th dan $\mathrm{U}$ yang terendapkan. Selain Mamuju, Mamasa dan Tana Toraja yang berada tepat di sebelah selatan dan tenggara Mamuju juga diinterpretasikan memiliki kandungan Th yang melebihi batas normal. Interpretasi tersebut selain didasarkan pada letak lokasi yang berdekatan, juga atas dasar adanya anomali pola unsur Th pada batuan plutonik dan volkanik di Mamasa dan Tana Toraja [4].
Potensi Th yang sangat bervariasi tersebut membuat perlunya dilakukan identifikasi detil mengenai formasi batuan, jenis batuan, hingga mineral pembawa Th di daerah sekitar Mamasa dan Tana Toraja. Identifikasi tersebut juga disertai dengan pendetilan mengenai proses evolusi magma dan tektonik yang berperan terhadap proses pengayaan unsur tersebut. Penelitian ini bertujuan untuk mengetahui mekanisme tataan tektonik yang berperan penting terhadap terjadinya peningkatan konsentrasi Th di Mamasa dan Tana Toraja.

\section{METODOLOGI}

Penelitian dilakukan di wilayah Kabupaten Mamasa, Provinsi Sulawesi Barat dan Kabupaten Tana Toraja, Provinsi Sulawesi Selatan (Gambar 1). Luas daerah penelitian tersebut mencapai $\pm 6.400 \mathrm{~km}^{2}$. Penelitian ini memiliki fokus pada batuan plutonik dan vulkanik (Gambar 2).

Analisis dilakukan melalui tiga pendekatan yang ditunjang dengan kegiatan observasi lapangan untuk mendapatkan data yang presisi dan akurat, sehingga hasil penelitian dapat dipertanggungjawabkan. Tiga pendekatan yang dimaksud yaitu analisis petrografi [8], analisis geokimia batuan, dan pentarikhan umur absolut.

Analisis petrografi dilakukan dengan menggunakan mikroskop polarisasi di Laboratorium Petrografi Institut Teknologi Bandung (ITB), sedangkan analisis geokimia batuan (Tabel 1 dan 2) dilakukan dengan menggunakan Atomic Absorption Spectrophotometry (AAS), Inductively Coupled Plasma-Mass Spectrometry (ICPMS), Neutron Activation (NA), dan X-Ray Fluorescence (XRF) [11-14]. Analisis geokimia batuan tersebut dilakukan dengan menggunakan fasilitas laboratorium di 
Université Bretagne Occidentale (UBO) UBO Prancis. Total sampel batuan yang Prancis dan ALS Chemex Kanada. digunakan untuk analisis tersebut berjumlah Pentarikhan umur absolut menggunakan enam buah (Gambar 2), terdiri dari empat metode ${ }^{40} \mathrm{~K}-{ }^{40} \mathrm{Ar}$ [11] yang memiliki data primer, dan dua data sekunder dari jangkauan kekeliruan maksimal $\pm 0,60$ million Elburg dan Foden [12]. years ago (Ma) dilakukan di Laboratorium

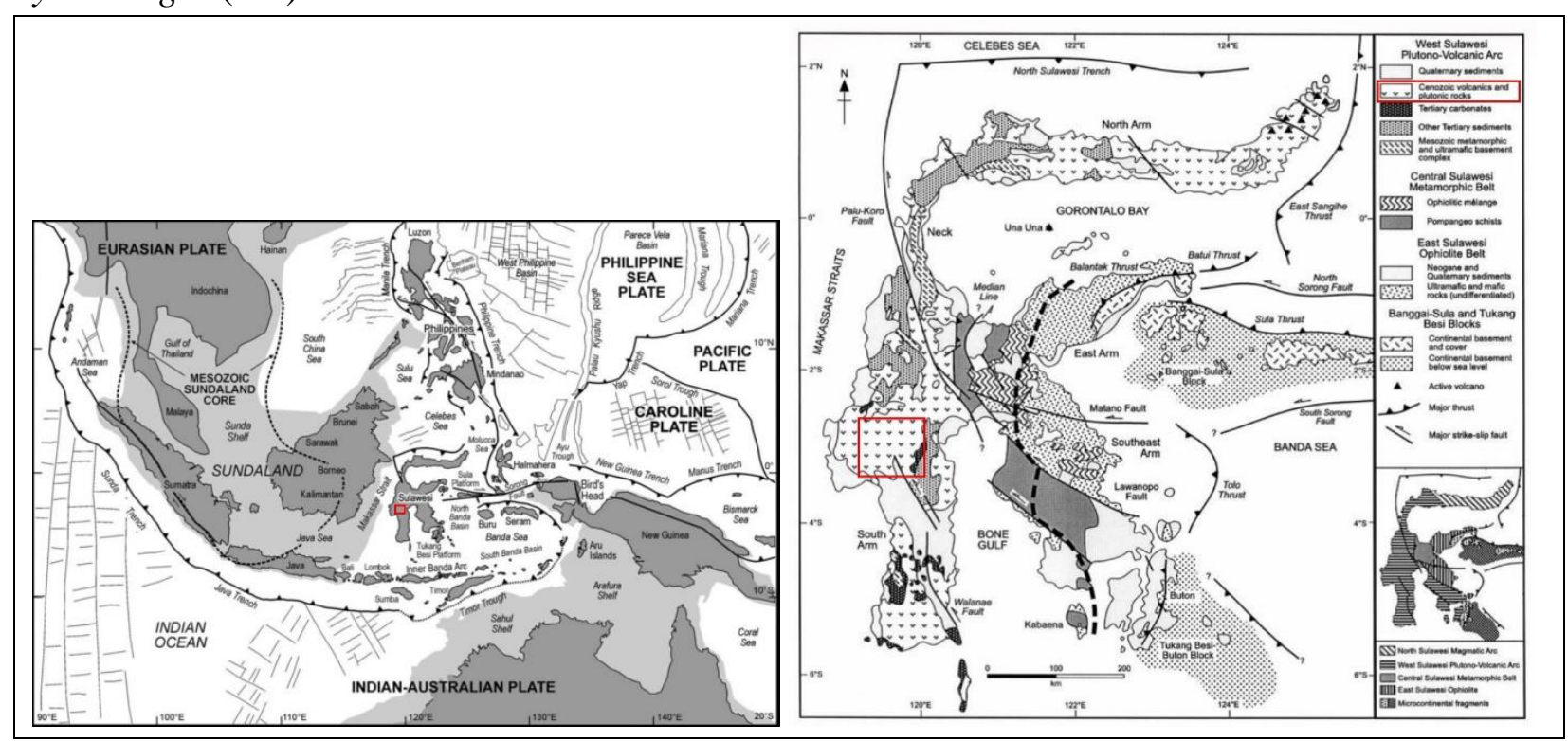

Gambar 1. Lokasi penelitian pada tataan tektonik Asia Tenggara [5] dan tektonik Sulawesi [6, 7].

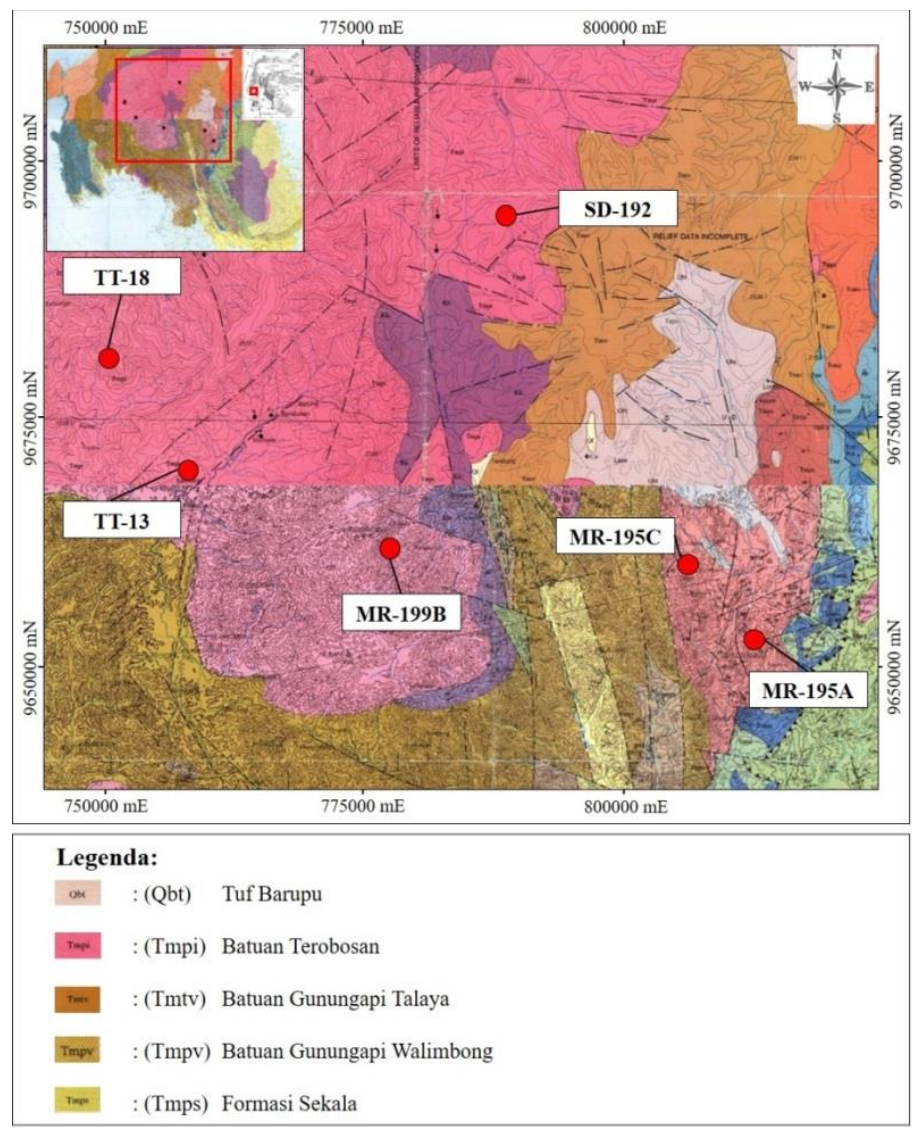

Gambar 2. Peta geologi daerah penelitian serta titik lokasi sampel batuan (modifikasi dari [9, 10]). 
Tabel 1. Data geokimia unsur utama (major elements) di daerah penelitian.

\begin{tabular}{lcccc}
\hline Sampel & MR-195C & SD-192 & TT-13 & \multicolumn{1}{c}{ TT-18 } \\
\hline $\begin{array}{c}\text { Umur } \\
\text { (Ma) }\end{array}$ & & $\mathbf{1 2 , 2 0 \pm 0 , 6 0}$ & & $\begin{array}{c}\mathbf{1 3 , 1 0} \pm \mathbf{1 0 , 1 1 -} \\
\mathbf{1 1 , 0 2} \pm \mathbf{0 , 0 9}\end{array}$ \\
\hline Analisis & $\begin{array}{c}\text { AAS } \\
\text { (wt.\%) }\end{array}$ & $\begin{array}{c}\text { AAS } \\
\text { (wt.\%) }\end{array}$ & $\begin{array}{c}\text { XRF } \\
\text { (wt.\%) }\end{array}$ & $\begin{array}{c}\text { XRF } \\
\text { (wt.\%) }\end{array}$ \\
\hline $\mathrm{SiO}_{2}$ & 46,70 & 48,30 & 47,81 & 45,39 \\
$\mathrm{TiO}_{2}$ & 1,22 & 1,02 & 1,09 & 1,25 \\
$\mathrm{Al}_{2} \mathrm{O}_{3}$ & 15,52 & 14,09 & 11,99 & 13,56 \\
$\mathrm{Fe}_{2} \mathrm{O}_{3}$ tot & 10,75 & 10,68 & 11,70 & 13,37 \\
$\mathrm{MnO}_{\mathrm{MgO}}$ & 0,19 & 0,19 & 0,19 & 0,19 \\
$\mathrm{CaO}$ & 6,63 & 5,03 & 8,29 & 6,76 \\
$\mathrm{Na}$ & 11,85 & 9,74 & 11,57 & 11,61 \\
$\mathrm{~K}_{2} \mathrm{O}$ & 1,93 & 2,10 & 1,82 & 2,06 \\
$\mathrm{P}_{2} \mathrm{O}$ & 1,89 & 4,39 & 4,11 & 3,67 \\
$\mathrm{LOI}$ & 0,50 & 0,70 & 1,19 & 1,84 \\
\hline $\mathrm{Total}$ & 1,63 & 2,06 & 0,56 & 0,13 \\
\hline
\end{tabular}

Tabel 2. Data geokimia unsur jejak (trace elements) di daerah penelitian.

\begin{tabular}{|c|c|c|c|c|c|c|c|c|}
\hline \multirow{2}{*}{$\begin{array}{l}\text { Sampel } \\
\text { Umur (Ma) }\end{array}$} & \multicolumn{2}{|c|}{ MR-195C } & \multicolumn{2}{|c|}{ SD-192 } & \multicolumn{2}{|c|}{ TT-13 } & \multicolumn{2}{|c|}{ TT-18 } \\
\hline & & & 12,2 & $\pm 0,60$ & & & $\begin{array}{l}13,10 \\
11,02\end{array}$ & $\begin{array}{l}\mathbf{0 , 1 1 -} \\
\pm 0,09\end{array}$ \\
\hline Analisis & $\begin{array}{c}\text { NA } \\
(\mathbf{p p m})\end{array}$ & $\begin{array}{l}\text { AAS } \\
(\mathbf{p p m})\end{array}$ & $\begin{array}{c}\text { NA } \\
(\mathbf{p p m})\end{array}$ & $\begin{array}{l}\text { AAS } \\
(\mathbf{p p m})\end{array}$ & $\begin{array}{c}\text { XRF } \\
(\mathbf{p p m})\end{array}$ & $\begin{array}{c}\text { ICP-MS } \\
\text { (ppm) }\end{array}$ & $\begin{array}{c}\text { XRF } \\
(\mathbf{p p m})\end{array}$ & $\begin{array}{c}\text { ICP-MS } \\
\text { (ppm) }\end{array}$ \\
\hline Cs & 1,40 & & 5,84 & & & & & \\
\hline $\mathrm{Rb}$ & & 53,00 & & 170,00 & 196,10 & & 192,10 & \\
\hline $\mathrm{Ba}$ & & 1405,00 & & 2420,00 & 3449,00 & & 3733,00 & \\
\hline $\mathrm{U}$ & 1,62 & & 2,74 & & & 2,50 & & 3,40 \\
\hline $\mathrm{Sr}$ & & 923,00 & & 912,00 & 1246,90 & & 1313,30 & \\
\hline $\mathrm{Th}$ & 9,17 & & 14,61 & & & 13,40 & & 17,90 \\
\hline $\mathrm{Ta}$ & 0,30 & & 0,38 & & & 0,43 & & 0,51 \\
\hline $\mathrm{La}$ & 22,31 & & 31,46 & & & 36,50 & & 52,00 \\
\hline $\mathrm{Nb}$ & & & & & & 5,30 & & 5,40 \\
\hline $\mathrm{Ce}$ & 50,90 & & 62,00 & & & 74,00 & & 104,60 \\
\hline $\mathrm{Nd}$ & & & & & & 36,80 & & 52,40 \\
\hline $\mathrm{Zr}$ & 72,00 & & 65,00 & & 99,50 & & 101,90 & \\
\hline $\mathrm{Hf}$ & 2,42 & & 3,61 & & & 3,14 & & 2,84 \\
\hline $\mathrm{Sm}$ & 5,29 & & 5,56 & & & 7,40 & & 10,03 \\
\hline $\mathrm{Eu}$ & 1,63 & & 1,63 & & & 1,83 & & 2,25 \\
\hline $\mathrm{Tb}$ & 0,66 & & 0,66 & & & 0,81 & & 0,98 \\
\hline $\mathrm{Y}$ & & & & & & 24,00 & & 27,80 \\
\hline Dy & & & & & & 4,20 & & 4,98 \\
\hline $\mathrm{Er}$ & & & & & & 2,20 & & 2,50 \\
\hline $\mathrm{Yb}$ & 2,12 & & 1,75 & & & 1,88 & & 1,95 \\
\hline $\mathrm{Pb}$ & & & & & & 44,20 & & 41,20 \\
\hline $\mathrm{Lu}$ & & & & & & 0,28 & & 0,29 \\
\hline
\end{tabular}

Ketiga pendekatan yang telah disebutkan sebelumnya, menghasilkan deskripsi petrografi detil dan berbagai macam jenis diagram korelasi. Deskripsi petrografi detil tersebut kemudian dipadukan dengan hasil analisis peta geologi untuk mengetahui 
formasi batuan, jenis batuan, serta mineral yang menjadi sumber dari tingginya kandungan Th, hal tersebut tentunya didukung dengan data geokimia batuan. Selanjutnya, dengan tambahan diagram- diagram korelasi, hasil-hasil tersebut digunakan untuk menjawab permasalahan mengenai proses evolusi magma dan tektonik yang menyebabkan kandungan Th di daerah penelitian menjadi tinggi.



Gambar 3. Petrografi dari sampel batuan (kiri-kanan): (a) MR-195A: Plagioklas [A2], montiselit [C5], nefelin [A5], alanit [D3], dan mineral opak [B5]; (b) MR-195C: Plagioklas [B2], olivin [D5], piroksen [D3], hornblenda [E6], mineral opak [A2], alanit [E5], dan phlogopit [C4]; (c) MR-199B: Montiselit [C1], nefelin [A6], mineral opak [B4], dan alanit [D2]; (d) SD-192: Plagioklas [C7], olivin [D4], hornblenda [B2], alanit [E2], dan mineral opak [E7].

\section{HASIL DAN PEMBAHASAN Petrografi}

Analisis petrografi dilakukan pada empat sampel batuan. Sampel MR-195A merupakan batuan vulkanik yang termasuk ke dalam Formasi Sekala (Tmps). Hasil pengamatan petrografi menunjukkan bahwa MR-195A memiliki tekstur holokristalin, inequigranular, porfiritik, dan poikilitik, serta sieve dan embayment pada plagioklas, montiselit, dan alanit (Gambar 3a). Mineral penyusun MR195A terdiri dari fenokris sebanyak $30 \%$ dan masa dasar sebanyak 70\%. Mineral yang hadir sebagai fenokris antara lain plagioklas, montiselit, nefelin, alanit, dan mineral opak. Mineral tersebut memiliki bentuk euhedralanhedral dengan ukuran 0,20-1,00 milimeter $(\mathrm{mm})$. Fenokris tersebut tertanam dalam masa dasar mikrokristalin plagioklas, montiselit, nefelin, piroksen, dan alanit. Sampel MR195A juga menunjukkan adanya ubahan yang dibuktikan oleh hadirnya mineral sekunder berupa oksida besi sebanyak 5\%. Sampel MR-195A secara petrografis merupakan 
nefelin-basanit $[8,15]$, yang memiliki tekstur khusus berupa aliran (trakitik) pada masa dasarnya.

Sampel MR-195C termasuk dalam Formasi Sekala. Sampel MR-195C merupakan basalt berdasarkan hasil analisis petrografi [8, 15]. Sampel MR-195C tidak memperlihatkan adanya tekstur trakitik seperti pada MR-195A. Tekstur basalt ini terdiri dari holokristalin, inequigranular, porfiritik, dan antipertit (Gambar 3b). Sebanyak $40 \%$ penyusun batuan ini adalah fenokris, berupa plagioklas, olivin, piroksen, hornblenda, mineral opak, alanit, dan phlogopit. Fenokris tersebut berukuran 0,101,00 mm dengan bentuk subhedral-anhedral. Masa dasar penyusun batuan pada sampel MR-195C berjumlah 60\% dan terdiri dari plagioklas, olivin, piroksen, hornblenda, dan mineral opak. Batuan ini telah mengalami ubahan sebanyak $2 \%$ berupa oksida besi. MR-195C terlihat memiliki struktur berupa vesikuler dan amigdaloidal.

MR-199B merupakan bagian dari Formasi Batuan Terobosan (Tmpi). Mineral penyusun batuan ini terdiri dari $20 \%$ fenokris berbentuk euhedral-anhedral dengan ukuran 0,30-1,50 mm dan 80\% masa dasar berukuran mikrokristalin (Gambar 3c). Montiselit, nefelin, mineral opak, dan alanit hadir sebagai fenokris dan masa dasar, sedangkan plagioklas hanya hadir sebagai masa dasar. MR-199B memiliki tekstur holokristalin, inequigranular, dan porfiritik. Nefelin-basanit $[8,15]$ merupakan nama petrografis dari MR199B.

Sampel batuan terakhir untuk analisis petrografi yaitu SD-192 yang secara petrografis merupakan trakhibasalt $[8,15]$. SD-192 tersusun oleh 35\% fenokris, dan $65 \%$ masa dasar berukuran mikrokristalin. Keduanya memiliki komposisi mineral yang sama, yaitu plagioklas, olivin, hornblenda, alanit, dan mineral opak (Gambar 3d). Ukuran fenokris berkisar antara 0,30-1,50 $\mathrm{mm}$ dengan bentuk euhedral-anhedral. Tekstur yang dijumpai pada sampel SD-192 diantaranya holokristalin, inequigranular, porfiritik, poikilitik, dan tekstur trakitik pada masa dasarnya. Trakhibasalt ini termasuk dalam Formasi Batuan Terobosan, dengan tingkat pelapukan tergolong segar.

Sampel TT-13 dan TT-18 (Gambar 2) secara petrografis merupakan gabro [12]. Kedua sampel batuan tersebut adalah batuan plutonik yang termasuk ke dalam Formasi Batuan Terobosan. Tingkat pelapukan batuan tersebut tergolong segar tanpa adanya tandatanda kemunculan mineral sekunder. Mineral penyusun TT-13 dan TT-18 memiliki ukuran antara 0,50-1,50 $\mathrm{mm}$ dengan bentuk subhedral-anhedral [12].

Analisis petrografi secara keseluruhan menunjukkan bahwa sampel batuan dari Formasi Sekala cenderung memiliki ukuran fenokris $\leq 1 \mathrm{~mm}$ dan telah mengalami ubahan sedangkan sampel batuan dari Formasi Batuan Terobosan terlihat lebih segar dengan ukuran fenokris mencapai > $1 \mathrm{~mm}$ (Gambar 3). Perbedaan tingkat pelapukan tersebut diindikasikan terkait dengan kondisi morfologi dan hidrologi yang berbeda antara masing-masing formasi batuan [4, 16]. Formasi Sekala berada di daerah dengan morfologi lebih landai dibandingkan Formasi Batuan Terobosan, sehingga dapat memiliki kondisi hidrologi yang lebih baik. Hal ini berpeluang menyebabkan potensi batuan untuk mengalami ubahan menjadi lebih besar. Di sisi lain, perbedaan ukuran fenokris sejalan dengan asal mula formasi batuannya. Fenokris pada sampel batuan dari Formasi Sekala terbentuk pada waktu yang lebih singkat dibandingkan dengan fenokris pada 
sampel batuan dari Formasi Batuan Terobosan yang memiliki waktu pembekuan magma yang lebih lama. Perbedaan ukuran fenokris tersebut juga dapat mengindikasikan magma pembentuk MR-195A dan MR-195C keluar ke permukaan sebagai hasil dari volkanisme eksplosif, sedangkan MR-199B dan SD-192 merupakan hasil dari volkanisme efusif $[13,17]$.

Mineral dari beberapa sampel batuan (Gambar 3) juga memperlihatkan tekstur khusus, seperti poikilitik (MR-195A; SD192), embayment (MR-195A), antipertit (MR195C), dan sieve (MR-195A). Tekstur poikilitik dan embayment mengindikasikan bahwa magma pembentuk batuan tersebut telah mengalami kontaminasi [16-18]. Material kontaminasi dapat berupa dinding dapur magma yang runtuh dan/atau batuan samping yang bereaksi dengan magma selama perjalanannya naik ke permukaan. Selain itu, hadirnya tekstur antipertit dan sieve memberikan indikasi bahwa telah terjadi perubahan kondisi tektonik selama berlangsungnya proses pembekuan magma atau pembentukan batuan [16-21].

Alanit yang hadir pada MR-195A, MR195C, MR-199B, dan SD-192 (Gambar 3), merupakan salah satu mineral yang memiliki kandungan unsur utama berupa Th dan U. Kandungan $\mathrm{Th}$ dan $\mathrm{U}$ pada alanit dapat mencapai 5 weight percent (wt.\%) torium dioksida $\left(\mathrm{ThO}_{2}\right)$ dan 0,50 wt.\% triuranium oktoksida $\left(\mathrm{U}_{3} \mathrm{O}_{8}\right)$, serta umumnya $20 \%$ dari berat total alanit didominasi oleh unsur tanah jarang (UTJ) [15, 22, 23]. Kandungan Th yang tinggi membuat alanit secara alamiah memiliki sifat radioaktif (Tabel 2). Alanit memiliki rumus kimia:

$$
\mathrm{Ca},(\mathrm{REE})^{3+} \mathrm{Al}_{2} \mathrm{Fe}^{2+}\left[\mathrm{Si}_{2} \mathrm{O}_{7}\right]\left[\mathrm{SiO}_{4}\right] \mathrm{O}(\mathrm{OH})
$$

dengan $\mathrm{Fe}^{2+}$ sebagai unsur yang paling berperan penting dalam mengikat UTJ [24].
Berdasarkan kehadiran alanit yang memiliki potensi untuk mengikat Th serta asosiasinya (termasuk UTJ) dalam jumlah besar maka nefelin-basanit, basalt, dan trakhibasalt dari Formasi Sekala dan Formasi Batuan Terobosan diindikasikan menjadi batuan pembawa Th. Alanit umumnya akan hadir sebagai mineral aksesori pada batuan yang bersifat felsik, seperti granit, granodiorit, hingga syenit [17, 24]. Kehadiran alanit pada batuan mafik di daerah penelitian merupakan suatu anomali, walaupun sebagian besar daerah penelitian relatif didominasi oleh batuan bersifat felsik. Hal itu menjadi salah satu alasan yang menguatkan indikasi telah terjadinya kontaminasi dan perubahan kondisi tektonik berdasarkan keterdapatan tekstur embayment dan sieve.

\section{Geokimia dan Umur Batuan}

Empat sampel batuan yaitu MR-195C, SD-192, TT-13, dan TT-18 digunakan untuk memenuhi kebutuhan analisis geokimia batuan. Hasil analisis menunjukkan bahwa keempat sampel batuan tersebut memiliki kandungan $\mathrm{SiO}_{2}$ antara 45-49 wt.\% dan Loss on Ignition (LOI) $<2,10$ wt.\% (Tabel 1). Kandungan LOI yang rendah memberikan keyakinan bahwa sampel batuan merupakan batuan segar, sehingga dapat disimpulkan kemungkinan terjadinya pengurangan atau penambahan kandungan kimia akibat proses sekunder sangat kecil.

Diagram korelasi $\mathrm{K}_{2} \mathrm{O}-\mathrm{SiO}_{2}$ (Gambar 4) modifikasi Maury [25] dari Peccerillo dan Taylor [26] memperlihatkan MR-195C, SD192, TT-13, dan TT-18 termasuk dalam kelompok afinitas batuan seri shoshonitik (SH). Secara kimiawi, nama batuan tersebut adalah absarokit, dengan batas kandungan $\mathrm{K}_{2} \mathrm{O}>1,50$ wt.\% dan $\mathrm{SiO}_{2}<53$ wt.\%. Kandungan $\mathrm{K}_{2} \mathrm{O}$ dari MR-195C paling rendah 
jika dibandingkan dengan tiga sampel batuan lainnya. Perbedaan tersebut mencerminkan magma pembentuk SD-192, TT-13, dan TT-
18 berasal dari Formasi Batuan Terobosan, mengalami pengayaan potasium lebih banyak dibandingkan batuan dari Formasi Sekala.

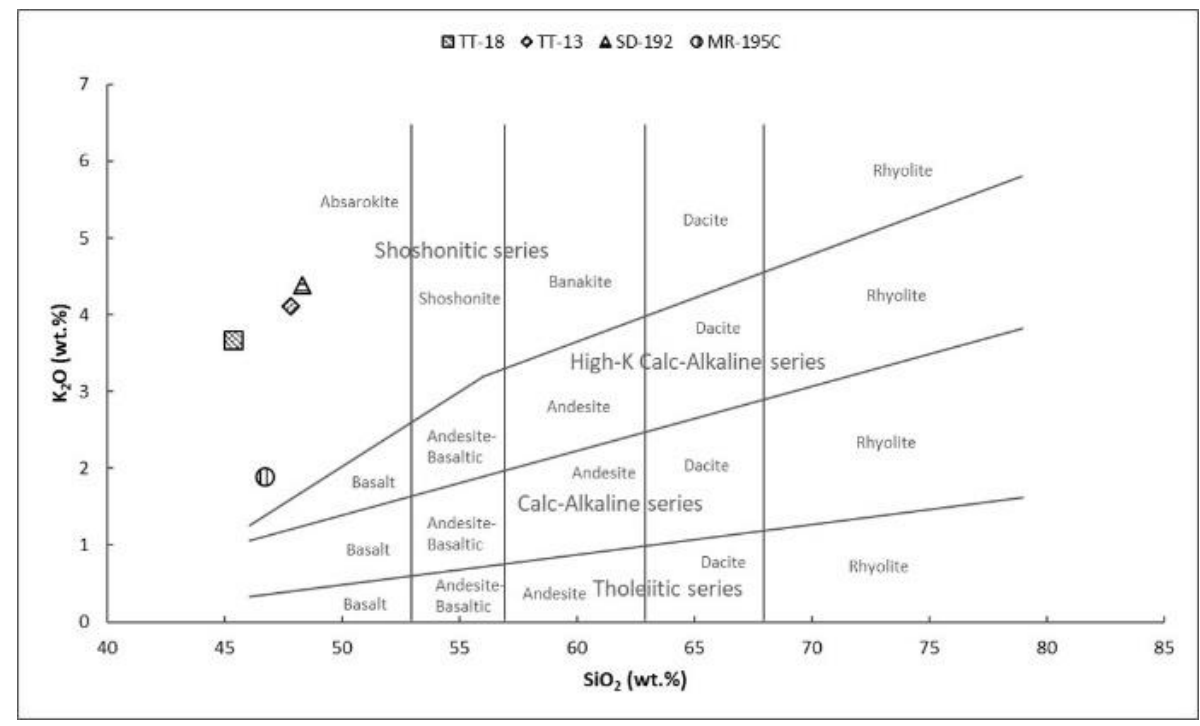

Gambar 4. Diagram korelasi $\mathrm{K}_{2} \mathrm{O}-\mathrm{SiO}_{2}$ (modifikasi [25] dari [26]).

Kandungan Th dan U pada MR-195C juga cenderung lebih rendah dibandingkan tiga sampel batuan dari Formasi Batuan Terobosan. Hasil analisis mencatat kandungan Th dan U dari MR-195C tidak lebih dari 10 parts per million ( $\mathrm{ppm}$ ) dan 2 ppm (Tabel 2). Perbandingan antara kandungan Th dan U yang digunakan untuk diagram korelasi $\mathrm{Th} / \mathrm{U}-\mathrm{SiO}_{2}$ memperlihatkan semua sampel batuan membentuk satu kelompok dengan nilai $\mathrm{Th} / \mathrm{U}$ berada di antara 5-6 (Gambar 5a), namun data K/Nb dari TT13 dan TT-18 pada diagram korelasi $\mathrm{K} / \mathrm{Nb}-$ $\mathrm{SiO}_{2}$ tidak membentuk satu kelompok (Gambar 5b). Secara umum, nilai $\mathrm{Th} / \mathrm{U}$ dan $\mathrm{K} / \mathrm{Nb}$ yang lebih tinggi dari batas rasio 2,50 $\mathrm{Th} / \mathrm{U}$ dan $2.100 \mathrm{~K} / \mathrm{Nb}$ (Gambar 5), mengindikasikan bahwa magma telah mengalami kontaminasi $[27,28]$. Hal tersebut sesuai dengan pernyataan Wilson bahwa secara umum Th dan $\mathrm{K}$ akan lebih banyak hadir pada batuan granitik dibandingkan basaltik [29].
Pola data geokimia MR-195C, SD-192, TT-13, dan TT-18 pada diagram laba-laba (Gambar 6a) dan diagram laba-laba diperluas (Gambar 6b) terlihat memiliki kemiripan dengan pola geokimia busur kepulauan (island arc/IA) dan batas kontinental aktif (active continental margin/ACM). Hal tersebut dipertegas dengan adanya pengayaan La-Nd (> 100 kali chondrite) dan penurunan $\mathrm{Nb}-\mathrm{Ta}-\mathrm{Ti}$ relatif terhadap La-Yb (Gambar 6) yang merupakan salah satu karakter proses subduksi [13, 14, 29].

Umur sampel SD-192 ditentukan dengan analisis ${ }^{40} \mathrm{~K}-{ }^{40} \mathrm{Ar}$ pada batuan utuh (wholerock), sedangkan umur pada sampel TT-18 didasarkan pada umur mineralnya (Gambar 6, Tabel 1 dan 2). Sampel SD-192 memiliki umur 12,20 Ma, dengan rentang kekeliruan $\pm 0,60$ Ma. Umur tersebut berada pada jangkauan umur TT-18, yang diketahui terbentuk sekitar 13,10 $\pm 0,11$ Ma hingga $11,02 \pm 0,09$ Ma berdasarkan hasil pentarikhan umur K-felspar dan biotit [12]. 
(a)


Gambar 5. Diagram korelasi: (a) $\mathrm{Th} / \mathrm{U}-\mathrm{SiO}_{2}$ [27]; (b) $\mathrm{K} / \mathrm{Nb}-\mathrm{SiO}_{2}$ [28].

Subduksi yang menghasilkan magma kaya Th diperkirakan terjadi sekitar umur Oligosen, tepatnya sebelum umur 13,10 Ma (Miosen). Magma tersebut memiliki komposisi Th yang tinggi karena mengalami penurunan kecepatan saat naik menuju permukaan, sehingga membuat proses kontaminasi berjalan lebih intensif.

\section{Batuan dan Mineral Pembawa Th}

Unsur radioaktif seperti Th umumnya hadir pada batuan yang mengandung UTJ dalam jumlah besar, terutama kelompok UTJ ringan (light rare earth elements/LREE)
(Tabel 2). Mineralisasi LREE banyak ditemukan pada kompleks batuan alkalin, granitik, terobosan, hingga trakhit dan vulkaniklastik [30-32], seperti nefelinbasanit, basalt, trakhibasalt, dan gabro di daerah penelitian (Gambar 2-4).

Batuan berkomposisi basaltik-andesitik yang mengandung LREE dalam jumlah besar serta memiliki Th sangat jarang terbentuk di Indonesia. Namun, beberapa batuan tersebut pernah ditemukan dalam bentuk trakhit dan leusit-basalt di sebagian wilayah Sulawesi Barat [33, 34], tepatnya di sebelah utara-barat laut daerah penelitian. 


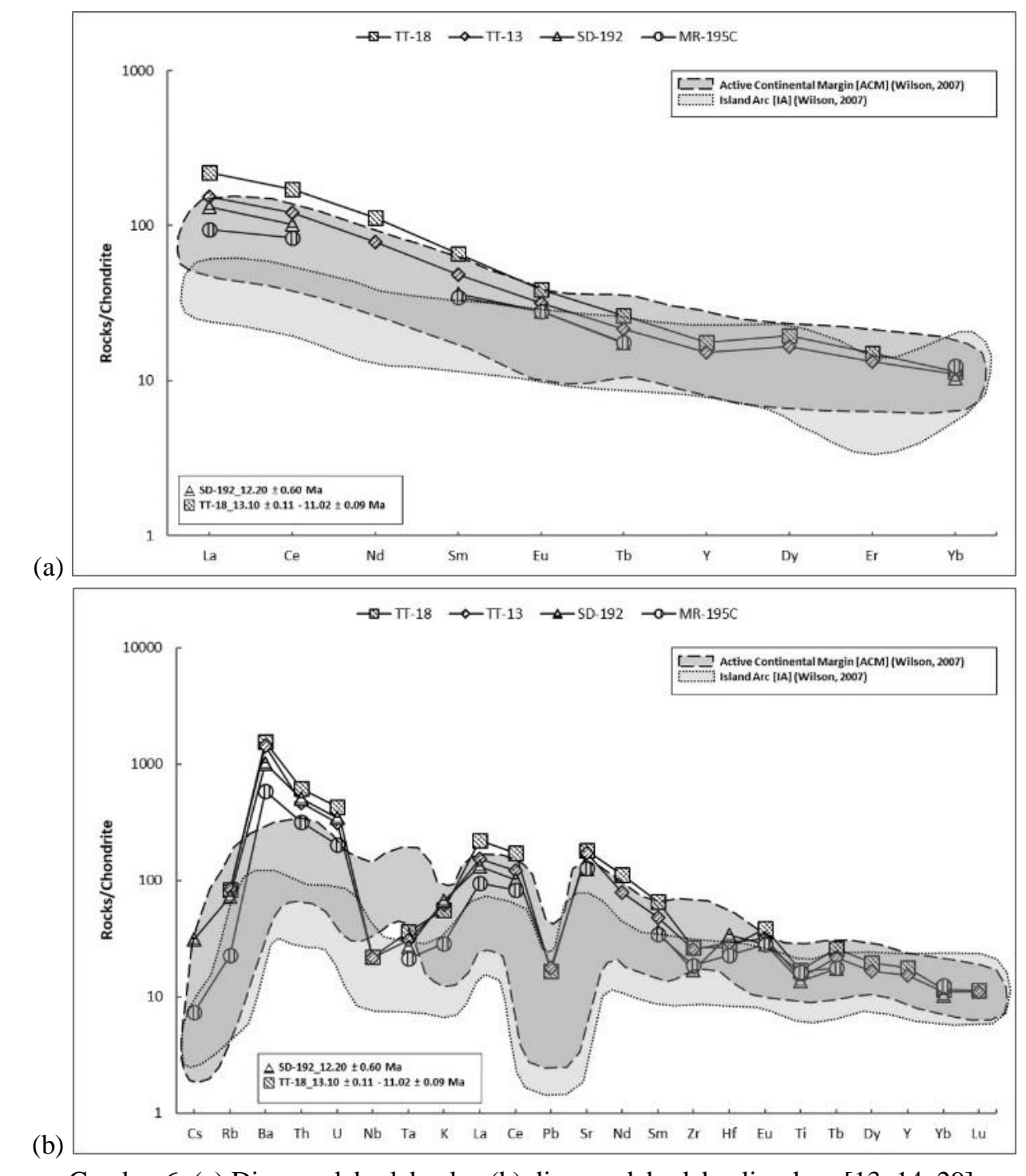

Gambar 6. (a) Diagram laba-laba dan (b) diagram laba-laba diperluas [13, 14, 29].

Batuan mafik tersebut mengikat Th dalam bentuk senyawa mineral, baik mineral primer maupun aksesori. Sumber mineral primer yang umumnya banyak membawa Th diantaranya bastnäsit, monasit, dan xenotime. Hampir 95\% sumber daya Th diperoleh dari tiga mineral tersebut [31, 35-37]. Namun, sumber mineral yang membawa Th di daerah penelitian bukanlah mineral primer, melainkan alanit yang merupakan bagian dari mineral aksesori (Gambar 3). Batuan dengan kumpulan mineral-mineral yang mampu mengikat LREE dalam jumlah besar diyakini ikut mendorong Th untuk terikat ke dalam senyawa kimia alanit [31, 38, 39]. Nefelinbasanit, basalt, trakhibasalt, dan gabro sebagai batuan, serta alanit sebagai mineral pembawa Th tersebut, merupakan bagian dari Formasi Sekala dan Formasi Batuan Terobosan (Gambar 2) yang terbentuk sekitar umur Miosen-Pliosen $[9,10]$.

\section{Evolusi Magma dan Tektonik}

Batuan dengan komposisi basaltik umumnya memiliki rata-rata konsentrasi Th sekitar 10,50 ppm [40, 41] dan U sekitar 3,00 ppm [41, 42]. Rata-rata konsentrasi tersebut akan semakin meningkat seiring dengan 
tingkat keasaman batuan. Sebagai contoh, granit/riolit memiliki rata-rata konsentrasi sekitar 15,00 ppm untuk Th dan 4,50 ppm untuk U [43-45], sehingga terlihat mengalami peningkatan sekitar $50 \%$ dari rata-rata konsentrasi Th dan U pada gabro/basalt.

Konsentrasi Th yang tinggi pada batuan mafik di daerah penelitian (Tabel 2) disebabkan oleh mekanisme pembekuan magma yang sangat ekstrim. Mekanisme tersebut terjadi akibat proses fraksionasi yang berjalan dengan sangat cepat $[41,46]$. Temperatur magma yang turun secara drastis akibat masuknya tambahan material dari luar sistem ke dalam magma menjadi penyebab terjadinya anomali tersebut.

Indikasi telah terjadinya kontaminasi juga sesuai dengan hasil penelitian terdahulu bahwa kehadiran U secara umum akan berkorelasi positif terhadap Th [45]. Korelasi antara keduanya yang termasuk sangat positif semakin memperlihatkan adanya pengaruh material dari luar sistem (Gambar 6b dan Tabel 2), yang diperkirakan berasal dari kerak mikro-kontinen blok barat daya Sulawesi [33].
Endapan Th beserta asosiasinya dapat ditemukan di berbagai lingkungan geologi, mulai dari lingkungan magmatik dan metamorfik hingga dekat permukaan [45]. Namun, umumnya kehadiran endapan tersebut hanya berada pada tingkat konsentrasi yang sangat rendah, karena untuk meningkatkan konsentrasi tersebut diperlukan kondisi khusus. Salah satu tataan tektonik yang sangat mendukung pembentukan Th adalah magmatisme dalam satu lempeng (continental within-plate) yang berasosiasi dengan sistem pemekaran, sesar, atau hotspot [31]. Asosiasi tersebut memungkinkan terjadinya peningkatan konsentrasi Th melalui proses transfer unsur dari kerak ke dalam magma.

Rezim tektonik yang mengalami perubahan dari subduksi aktif menjadi postsubduksi berperan sebagai kondisi khusus di daerah penelitian. Hasil korelasi antara $\mathrm{K}_{2} \mathrm{O}$ $\mathrm{SiO}_{2}$ dari sampel batuan di daerah penelitian yang dikombinasikan dengan pembagian tataan tektonik [11], sangat jelas memperlihatkan sampel batuan berada dalam cakupan area post-subduksi (Gambar 7).



Gambar 7. Pembagian tataan tektonik menggunakan hasil korelasi $\mathrm{K}_{2} \mathrm{O}-\mathrm{SiO}_{2}$ [11]. 
Sejak dimulainya proses peralihan dari subduksi aktif, hingga akhirnya menjadi postsubduksi, temperatur dan kecepatan magma mengalami penurunan secara drastis. Keadaan tersebut menjadikan kontaminasi dan asimilasi berperan sangat aktif dalam memodifikasi komposisi magma. Modifikasi tersebut memperkaya kandungan Th beserta asosiasinya pada batuan yang terbentuk di daerah penelitian.

Perubahan rezim tektonik di daerah penelitian diperkirakan terjadi pada umur Oligosen (33,90-23,03 Ma). Pembentukan batuan yang berasosiasi langsung dengan subduksi aktif di lengan barat Sulawesi (Tana Toraja-Makassar) berakhir pada umur $\pm 29,90$ Ma [11]. Akhir pembentukan batuan tersebut menjadi pertanda awal dimulainya peralihan rezim tektonik di daerah penelitian.

\section{KESIMPULAN}

Batuan di daerah penelitian terdiri dari nefelin-basanit, basalt, trakhibasalt, dan gabro, yang secara kimia disebut sebagai absarokit. Salah satu mineral penyusun batuan tersebut adalah alanit yang memiliki komposisi Th yang tinggi. Batuan-batuan tersebut termasuk ke dalam Formasi Sekala dan Formasi Batuan Terobosan. Daerah penelitian terbentuk pada batas kontinental aktif, berupa zona subduksi yang mengalami perubahan kondisi dari subduksi aktif menjadi post-subduksi. Perubahan kondisi tersebut menyebabkan magma mengalami kontaminasi yang sangat intensif. Tekanan dan temperatur yang secara mendadak berubah drastis membuat ketahanan kerak menjadi berkurang dan akhirnya masuk ke dalam magma. Proses naiknya magma ke permukaan menjadi semakin lambat pada rezim post-subduksi karena hilangnya tekanan secara signifikan. Hal tersebut membuat proses asimilasi antara magma dengan batuan samping berjalan lebih maksimal. Rezim post-subduksi juga mempercepat proses pendinginan magma sehingga Th beserta asosiasinya turut menjadi unsur pembentuk mineral.

\section{UCAPAN TERIMA KASIH}

Terima kasih kepada Chevron Indonesia atas dukungan dana yang diberikan untuk kebutuhan akomodasi dan transportasi selama kegiatan lapangan.

\section{DAFTAR PUSTAKA}

[1] P. Faure, M. A. Bouhifd, M. Boyet, G. Manthilake, V. Clesi, dan J.-L. Devidal, "Uranium and thorium partitioning in the bulk silicate earth and the oxygen content of earth's core," Geochim. Cosmochim. Acta, vol. 275, pp. 83-98, Apr. 2020, doi 10.1016/j.gca.2020.02.010.

[2] M. Khairani, Sutrisno, dan F. D. Indrastomo, "Identifikasi uranium dan thorium di Desa Takandeang, Mamuju, Sulawesi Barat, dengan menginterpretasikan data radiometri tanah atau batuan," Al-Fiziya J. Mater. Sci. Geophys. Instrum. Theor. Phys., vol. 1, no. 1, Apr. 2018, doi: 10.15408/fiziya.v1i1.8993.

[3] F. R. Mu'awanah, B. Priadi, W. Widodo, I. G. Sukadana, dan R. Andriansyah, "Uranium mobilty on active stream sediment in Mamuju Area, West Sulawesi," Eksplorium, vol. 39, no. 2, pp. 95-104, Nov. 2018, doi: 10.17146/eksplorium.2018.39.2.4953.

[4] S. P. Saputro, Magmatism of High Potassium in Tana Toraja, Bandung: Bandung Institute of Technology (ITB), 2017.

[5] R. Hall dan M. E. J. Wilson, "Neogene sutures in eastern Indonesia," J. Asian Earth Sci., vol. 18, no. 6, pp. 781-808, Dec. 2000, doi: 10.1016/S1367-9120(00)00040-7.

[6] A. Kadarusman, S. Miyashita, S. Maruyama, C. D. Parkinson, dan A. Ishikawa, "Petrology, geochemistry, and paleogeographic reconstruction of the East Sulawesi Ophiolite, Indonesia," Tectonophysics, vol. 392, no. 1-4, pp. 55-83, Nov. 2004, doi: 10.1016/j.tecto.2004.04.008. 
[7] A. Maulana, K. Watanabe, A. Imai, dan K. Yonezu, "Origin of magnetite- and ilmeniteseries granitic rocks in Sulawesi, Indonesia: Magma genesis and regional metallogenic constraint," Procedia Earth Planet. Sci., vol. 6, pp. 50-57, 2013, doi: 10.1016/j.proeps.2013.01.007.

[8] M. J. Hibbard, Petrography to Petrogenesis, Englewood Cliffs, New Jersey: Prentice-Hall, 1995.

[9] N. Ratman dan S. Atmawinata, Geological Map of the Mamuju Quadrangle, Sulawesi, Scale 1:250000, Bandung: Geological Research and Development Centre, 1993.

[10] Djuri, Sudjatmiko, S. Bachri, dan Sukindo, Geological Map of the Majene and the Western Part of Palopo Sheets, Sulawesi, Scale 1:250000, Bandung: Geological Research and Development Centre, 1998.

[11] B. Priadi, Geochimie du Magmatisme de l'ouest et du Nord de Sulawesi, Indonesie. Traçage des Sources et Implications Géodynamiques, France: Univ. P. Sabatier, 1993.

[12] M. Elburg dan J. Foden, "Sources for magmatism in Central Sulawesi: Geochemical and $\mathrm{Sr}-\mathrm{Nd}-\mathrm{Pb}$ isotopic constraints," Chem. Geol., vol. 156, no. 1-4, pp. 67-93, Apr. 1999, doi: 10.1016/S00092541(98)00175-2.

[13] J. D. Winter, Principles of Igneous and Metamorphic Petrology, 2nd ed., vol. 2. Edinburgh Gate, Harlow: Pearson Prentice Hall, 2014.

[14] S. P. Saputro dan B. Priadi, "Penyebab serta sumber high-K pada batuan volkanik dan plutonik di Tana Toraja, Sulawesi Selatan bagian utara: Terkait kerak, evolusi magma, dan rezim tektonik," in Proceeding Seminar Nasional Kebumian ke-9, 2016, pp. 412-420.

[15] R. H. Vernon, A Practical Guide to Rock Microstructure, 2nd ed. Cambridge: Cambridge University Press, 2018.

[16] W. A. Deer, R. A. Howie, dan J. Zussman, RockForming Minerals, Manchester: The Geological Society Publishing House, 1998.

[17] D. Shelley, Igneous and Metamorphic Rocks under the Microscope, London: Chapman \& Hall, 1983.

[18] R. H. Vernon, A Practical Guide to Rock Microstructure, 1st ed. Cambridge: Cambridge University Press, 2004.

[19] E. W. M. Heinrich, Microscopic Petrography,
New York: McGraw-Hill Company, 1956.

[20] K. G. Cox, J. D. Bell, dan R. J. Pankhurst, The Interpretation of Igneous Rocks. Dordrecht: Springer Netherlands, 1979.

[21] P. C. Rickwood, "The largest crystals," Am. Mineral., vol. 66, no. 9-10, pp. 885-907, 1981.

[22] H. Fossen, Structural Geology, $2^{\text {nd }}$ ed. Cambridge: Cambridge University Press, 2016.

[23] C. W. Passchier dan R. A. J. Trouw, Microtectonics, $2^{\text {nd }}$ ed. Berlin, Heidelberg: Springer-Verlag, 2005.

[24] R. H. Vernon dan G. L. Clarke, Principles of Metamorphic Petrology. Cambridge: Cambridge University Press, 2008.

[25] R. C. Maury, "Les conséquences volcaniques de la subduction," Bull. Soc. Geol. France XXIV, vol. 17, no.3, pp. 489-500, 1984, doi: 10.2113/gssgfbull.S7-XXVI.3.489.

[26] A. Peccerillo dan S. R. Taylor, "Geochemistry of Eocene Calc-Alkaline volcanic rocks from the Kastamonu Area, northern Turkey," Contrib. to Mineral. Petrol., vol. 58, no. 1, pp. 63-81, 1976, doi: 10.1007/BF00384745.

[27] A. Maulana, K. Watanabe, A. Imai, dan K. Yonezu, "Petrology and geochemistry of granitic rocks in South Sulawesi, Indonesia: Implication for origin of magma and geodynamic setting," World Acad. Sci. Eng. Technol., vol. 61, no. 1, pp. 8-13, 2012, doi: 10.5281/zenodo.1328100.

[28] R. Hébert et al., "Miocene post-collisional shoshonites dan their crustal xenoliths, Yarlung Zangbo Suture Zone southern Tibet: Geodynamic implications," Gondwana Res., vol. 25, no. 3, pp. 1263-1271, Apr. 2014, doi: 10.1016/j.gr.2013.05.013.

[29] M. Wilson, Igneous Petrogenesis A Global Tectonic Approach, 1st ed. Dordrecht: Springer Netherlands, 2007.

[30] J. Dostal, "Rare earth element deposits of alkaline igneous rocks," resources, vol. 6, no. 34, pp. 112, 2017, doi: 10.3390/resources6030034.

[31] V. Balaram, "Rare earth elements: A review of applications, occurrence, exploration, analysis, recycling, and environmental impact," Geosci. Front., vol. 10, no. 4, pp. 1285-1303, Jul. 2019, doi: 10.1016/j.gsf.2018.12.005.

[32] N. M. Batapola et al., "A comparison of global rare earth element (REE) resources and their mineralogy with REE prospects in Sri Lanka," $J$. Asian Earth Sci., p. 104475, Jul. 2020, doi: 10.1016/j.jseaes.2020.104475. 
[33] I. G. Sukadana, A. Harijoko, dan L. D. Setijadji, "Tectonic setting of Adang Volcanic Complex in Mamuju Region, West Sulawesi Province," Eksplorium, vol. 36, no. 1, pp. 31-44, May 2015, doi: 10.17146/eksplorium.2015.36.1.2769.

[34] A. G. Muhammad, F. D. Indrastomo, dan I. G. Sukadana, "Resistivity and conductivity pattern of rock containing radioactive minerals in Botteng and Takandeang, Mamuju, West Sulawesi," Eksplorium, vol. 38, no. 1, pp. 49-62, 2017.

[35] D. Guo dan Y. Liu, "Occurrence and geochemistry of bastnäsite in carbonatite-related REE deposits, Mianning-Dechang REE belt, Sichuan Province, SW China," Ore Geol. Rev., vol. 107, no. April 2018, pp. 266-282, Apr. 2019, doi: 10.1016/j.oregeorev.2019.02.028.

[36] R. Prassanti et al., "Uranium precipitation in Bangka Monazite as ammonium diuranate (ADU) using NH3 gas," Eksplorium, vol. 41, no. 1, pp. 45-52, May 2020, doi: 10.17146/eksplorium.2020.41.1.5879.

[37] A. S. L. Sjöqvist, T. Zack, D. K. Honn, dan E. F. Baxter, "Modification of a rare-earth element deposit by low-temperature partial melting during metamorphic overprinting: Norra Kärr alkaline complex, southern Sweden," Chem. Geol., vol. 545, no. April, p. 119640, Jul. 2020, doi: 10.1016/j.chemgeo.2020.119640.

[38] G. Estrade, E. Marquis, M. Smith, K. Goodenough, dan P. Nason, "REE concentration processes in ion adsorption deposits: Evidence from the Ambohimirahavavy alkaline complex in Madagascar," Ore Geol. Rev., vol. 112, no. March, p. 103027, Sep. 2019, doi: 10.1016/j.oregeorev.2019.103027.

[39] S. Imashuku dan K. Wagatsuma, "Rapid identification of rare earth element bearing minerals in ores by cathodoluminescence method," Miner. Eng., vol. 151, no. December 2019, p. 106317, Jun. 2020, doi: 10.1016/j.mineng.2020.106317.

[40] R. L. Rudnick dan S. Gao, "Composition of the continental crust," Treatise on Geochemistry, vol. 3, no. 1, pp. 1-64, 2003, doi: 10.1016/B0-08043751-6/03016-4.

[41] I. W. Hadlich, A. C. B. Neto, N. F. Botelho, dan V. P. Pereira, "The thorite mineralization in the Madeira Sn-Nb-Ta world-class deposit (Pitinga, Brazil)," Ore Geol. Rev., vol. 105, no. November 2018, pp. 445-466, Feb. 2019, doi: 10.1016/j.oregeorev.2019.01.004.

[42] S. P. Jr. Clark, Z. E. Peterman, dan K. S. Heier, "Abundances of uranium, thorium, and potassium." In: S. P. Jr. Clark (ed.), Handbook of Physical Constants, Geological Society of America, vol. 97, pp. 521-541, 1966.

[43] M. Cuney dan K. Kyser, Recent and not-sorecent developments in uranium deposits and implications for exploration, Québec: Mineralogical Association of Canada, 2008.

[44] W. T. Chen dan M. F. Zhou, "Paragenesis, stable isotopes, and molybdenite Re-Os isotope age of the Lala iron-copper deposit, Southwest China," Economic Geology, vol. 107, no. 3, pp. 459-480, 2012, doi: 10.2113/econgeo.107.3.459.

[45] H. Song et al., "Uranium enrichment in the Lala $\mathrm{Cu}-\mathrm{Fe}$ deposit, Kangdian Region, China: A new case of uranium mineralization associated with an IOCG system," Ore Geol. Rev., vol. 121, no. March 2019, p. 103463, Jun. 2020, doi: 10.1016/j.oregeorev.2020.103463.

[46] M. Cuney, "Evolution of uranium fractionation processes through time: Driving the secular variation of uranium deposit types," Economic Geology, vol. 105, no. 3, pp. 553-569, 2010, doi: 10.2113/gsecongeo.105.3.553. 